Gut and Liver, Vol. 11, No. 1, January 2017, pp. 62-72

\title{
Effectiveness of Capsule Endoscopy Compared with Other Diagnostic Modalities in Patients with Small Bowel Crohn's Disease: A Meta-Analysis
}

\author{
Miyoung Choi ${ }^{1}$, Sungwon Lim ${ }^{1}$, Myung-Gyu Choi ${ }^{2}$, Ki-Nam Shim ${ }^{3}$, and Seon Heui Lee ${ }^{4}$ \\ ${ }^{1}$ National Evidence-based Healthcare Collaborating Agency, ${ }^{2}$ Department of Internal Medicine, The Catholic University of Korea College of \\ Medicine, ${ }^{3}$ Department of Internal Medicine, Ewha Womans University School of Medicine, Seoul, and ${ }^{4}$ Department of Nursing Science, College \\ of Nursing, Gachon University, Incheon, Korea
}

\section{See editorial on page 5.}

Background/Aims: As a result of the rapid development of medical diagnostic tools, physicians require concrete evidence to evaluate the effectiveness of the tools. We aimed to investigate the effectiveness and additional diagnostic benefits of capsule endoscopy (CE) in patients with small bowel Crohn's disease (CD). Methods: We performed a systematic search of databases, including MEDLINE, EMBASE, and the Cochrane Library, as well as eight domestic databases. Two reviewers independently screened all references. Diagnostic data from the studies were collected, and a meta-analysis was performed. Results: Twenty-four studies were included. In cases of suspected CD, CE demonstrated a superior diagnostic yield compared with small bowel follow-through (SBFT) and enteroclysis (EC); however, there was no difference compared with computed tomography enterography or magnetic resonance enterography. In cases with established CD, CE demonstrated a higher diagnostic yield only compared with EC. In the detection of terminal ileum lesions, CE exhibited a significantly increased detection rate compared with ileoscopy. Conclusions: The findings of our meta-analysis indicate that CE is superior to SBFT and EC in the evaluation of suspected CD cases. CE is also a more effective diagnostic modality in patients with established CD compared with EC. (Gut Liver 2017;11:62-72)

Key Words: Capsule endoscopy; Diagnostic yield; Metaanalysis; Intestine, small; Crohn disease

\section{INTRODUCTION}

Crohn's disease (CD) is an inflammatory bowel disease that can affect the entire gastrointestinal tract, although the small bowel is the most commonly affected site. ${ }^{1}$ According to population-based epidemiologic studies, $>50 \%$ of CD patients in Western countries $^{2-4}$ and up to $77.0 \%$ to $87.7 \%$ of $\mathrm{CD}$ patients in Asian countries had small bowel involvement at diagnosis. ${ }^{5,6}$ Therefore, the evaluation of the small and large intestine is essential for the diagnosis of $\mathrm{CD}$, although no pathognomonic features have been identified for endoscopic and radiologic studies. Such an evaluation is particularly vital in cases where ileoscopy is unsuccessful or where the distal ileum is not involved.

Small bowel radiography (e.g., small bowel follow-through [SBFT] and enteroclysis [EC]), colonoscopy with ileoscopy, and push enteroscopy (PE) are commonly available modalities for small bowel evaluation. Due to the limitations of each technique, it is difficult to adequately assess small bowel disease, particularly in cases with subtle mucosal changes or wherein the distal ileum is not involved. Considerable technological advancements, such as capsule endoscopy (CE), computed tomography enterography (CTE), and magnetic resonance enterography (MRE) have recently enabled a more accurate investigation of the small bowel.

Several previous meta-analyses have indicated that CE has superior diagnostic effectiveness, as compared to other modalities. ${ }^{7,8}$ Rapid technological advancements have been made in the era of CE and radiological evaluations, including CTE or MRE. In the present study, we aimed to evaluate the diagnostic yield of CE, compared with other diagnostic modalities, in patients with suspected and established $\mathrm{CD}$, using previous and newly

\footnotetext{
Correspondence to: Ki-Nam Shim ${ }^{a}$ and Seon Heui Lee

${ }^{a}$ Department of Internal Medicine, Ewha Womans University School of Medicine, 1071 Anyangcheon-ro, Yangcheon-gu, Seoul 07985, Korea Tel: +82-2-2650-2632, Fax: +82-2-2655-2076, E-mail: shimkn@ewha.ac.kr

bepartment of Nursing Science, College of Nursing, Gachon University, 191 Hambangmoe-ro, Yeonsu-gu, Incheon 21936, Korea

Tel: +82-32-820-4235, Fax: +82-32-820-4201, E-mail: sunarea87@gachon.ac.kr

Received on January 3, 2016. Revised on March 2, 2016. Accepted on May 10, 2016. Published online October 13,2016 pISSN 1976-2283 eISSN 2005-1212 https://doi.org/10.5009/gnl16015

@ This is an Open Access article distributed under the terms of the Creative Commons Attribution Non-Commercial License (http://creativecommons.org/licenses/by-nc/4.0) which permits unrestricted non-commercial use, distribution, and reproduction in any medium, provided the original work is properly cited.
} 
published studies.

\section{MATERIALS AND METHODS}

\section{Search strategy}

A literature search was performed using core databases such as MEDLINE, EMBASE, and Cochrane Library, for all articles published up to March 2014. Moreover, eight domestic research databases were searched, including KoreaMed and KMBASE. Furthermore, manual searches were also performed. After reviewing previous related studies and abstracts, key clinical questions regarding the safety and effectiveness of $\mathrm{CE}$, as well as the patient, intervention, comparators and outcomes (PICO) factors, were defined. The search terms were related to the intervention, and modified according to the index terms of each database, such as Medical Subject Heading (MeSH) and EMTREE. Extensive searches of the databases were performed using keywords such as "capsule endoscopy", "VCE", "SBCE", and "WCE."

\section{Study selection criteria}

Study selection was performed based on predefined inclusion/ exclusion criteria. Studies that met the following criteria were included: (1) the study population included patients with small bowel CD; (2) the intervention was CE; (3) study design included randomized controlled trials, nonrandomized studies, and diagnostic studies; (4) modalities compared included PE, CTE, MRE, and EC; (5) one of the predetermined outcomes was reported; and (6) the language was English or Korean.

Studies on animals or preclinical studies, as well as articles other than original articles (e.g., reviews, editorials, letters, con- ference abstracts, and comments) were excluded. Articles not published in either English or Korean, and studies with duplicate subjects (i.e., different studies using the same outcome indicators in the same patient) were also excluded.

\section{Outcomes}

Diagnostic yield and diagnostic accuracy were the main outcome indicators of the effectiveness of CE. Patient satisfaction, therapeutic impact on further treatment, and additional diagnostic information gain in comparison to other modalities were considered as secondary outcomes. Capsule retention, incomplete diagnostic information, and other complications related to the CE procedure were investigated as safety outcomes.

\section{A quality appraisal tool: Quality Assessment of Diagnostic Accuracy Studies-II}

Determination of study design quality was performed using the Quality Assessment of Diagnostic Accuracy Studies-II (QUADAS-II) tool. ${ }^{9}$ QUADAS-II is a quality appraisal tool used in diagnostic studies. The four domains comprise patient selection, index test, reference standard, and flow and timing. The risk of bias and applicability of concerns were determined for individual studies, and were graded as "low," "high," or "unclear." Some items were modified according to the PICO factors, such as in cases where the predefined threshold or cutoff was not applicable; in these cases, researchers did not evaluate these items.

There is no single reference standard for the diagnosis of suspected CD. After consulting a methodologist, the opinion of clinical experts or consensus among experts, based on all the

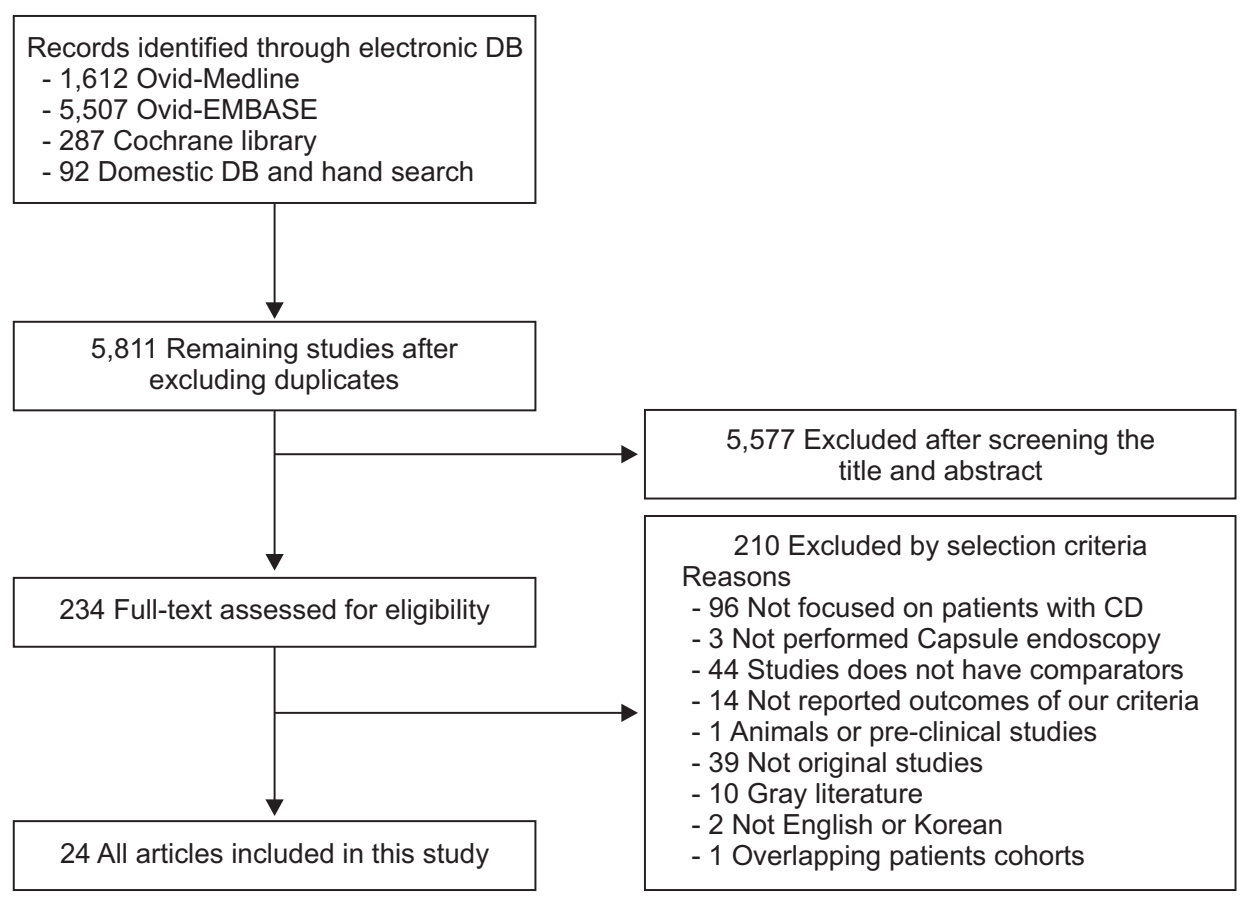

Fig. 1. Flow diagram of the study selection process. DB, database; CD, Crohn's disease. 


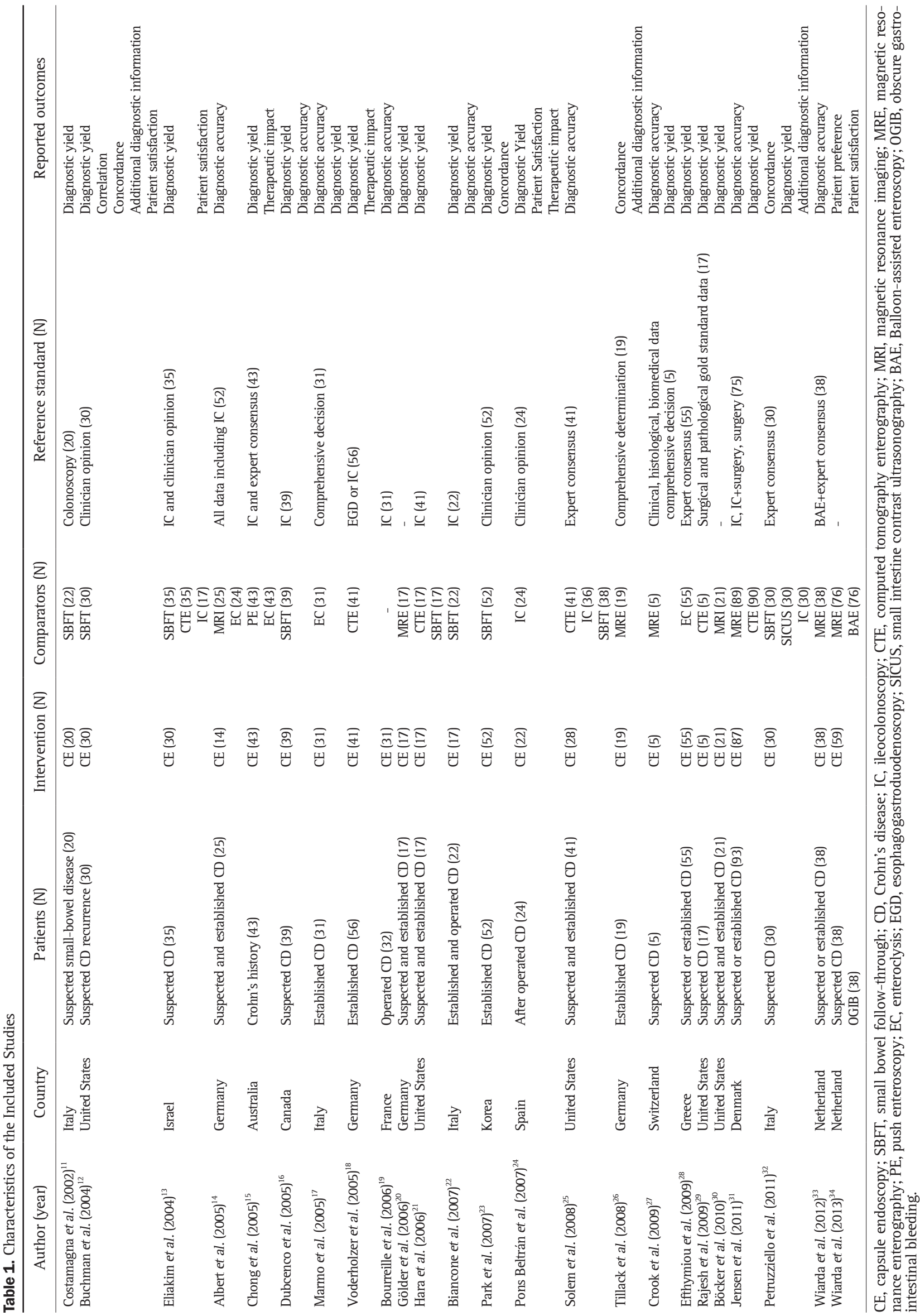


available tests performed for suspected $\mathrm{CD}$, was considered as a reference standard.

\section{Data extraction and analysis}

Using a pre-agreed data extraction format, two investigators independently extracted the data for review. The diagnostic yield, weighted incremental yield (IYw), and 95\% confidence interval (CIs) were calculated..$^{10}$ A random effect model was used to account for heterogeneity. However, in subgroup analysis, we used a fixed model for data that showed low heterogeneity. The extracted data were synthesized both quantitatively and qualitatively. A group of experts, comprising gastrointestinal clinicians and evidence-based medicine specialists, guided each stage. Statistical analysis was performed using Cochrane RevMan version 5.3 (The Nordic Cochrane Centre, The Cochrane Collaboration, 2014; RevMan, Copenhagen, Denmark).

\section{RESULTS}

\section{Study characteristic and quality assessment}

All the stages, from the literature search to the application of the selection criteria and data extraction, were independently performed by two researchers. A total of 7,498 studies were retrieved from the database. After exclusion of duplicates, 5,811 studies remained. Finally, 24 studies $^{11-34}$ were selected according to the selection and exclusion criteria (Fig. 1). The study characteristics are presented in Table 1 . The findings of the quality assessment of all the included studies, using the QUADAS-II tool, are shown in Fig. 2. The "reference standard" domain showed a relatively low rate of "low risk of bias" as compared to the others.

\section{Comparison of diagnostic yield}

The diagnostic yield was reported in 19 studies. The data were analyzed according to the target population, including those with suspected or established CD.

In patients with suspected CD, CE was compared to SBFT, EC, CTE, and MRE (Fig. 3). A total four studies ${ }^{11,13,16,32}$ compared CE and SBFT, but one study ${ }^{32}$ was excluded in the meta-analysis because of high heterogeneity in the patient selection. The diagnostic yield of CE was statistically higher than that of SBFT (CE, 66.0\% vs SBFT, 21.3\%; IYw, 0.44; 95\% CI, 0.29 to 0.59; $\mathrm{I}^{2}$, $30 \%)$. CE was compared with EC in two studies. ${ }^{14,28} \mathrm{CE}$ showed a superior diagnostic yield as compared to EC (CE, 75.7\% vs EC, 29.4\%; IYw, 0.50; 95\% CI, 0.21 to 0.79; I², 52\%). However, CE did not show a superior diagnostic yield as compared to CTE in two studies ${ }^{13,29}$ (CE, 72.5\% vs CTE, 22.5\%; IYw, 0.36; 95\% CI, 0.18 to $\left.0.90 ; \mathrm{I}^{2}, 68 \%\right)$. Moreover, CE did not show a significant superior diagnostic yield as compared to MRE in two studies (CE, 85.7\% vs MRE, 100\%; IYw, -0.16; 95\% CI, -0.63 to 0.32; $\mathrm{I}^{2}$, $44 \%)^{20,27}$

In patients with established $\mathrm{CD}, \mathrm{CE}$ only showed a statistically superior diagnostic yield as compared to EC group in four studies (CE, 68.5\% vs EC, 36.7\%; IYw, 0.39; 95\% CI, 0.28 to 0.50; $\left.\mathrm{I}^{2}, 0 \%\right)^{14,15,17,28}$ The diagnostic yield of other modalities, such as SBFT, CTE, MRE, and IC, was not significantly different as compared to that of CE (Fig. 4).

\section{Diagnostic accuracy}

The reference standards varied in the included studies. Therefore, quantitative data was not synthesized for the calculation of diagnostic accuracy, although the sensitivity and specificity were calculated (Table 2).

In patients with suspected $\mathrm{CD}$, two studies reported that the sensitivity and specificity of CE were $62 \%$ to $100 \%$ and $50 \%$ to $100 \%$, whereas those for MRE were $77 \%$ and $80 \%$, respectively. ${ }^{14,16}$ SBFT had the lowest sensitivity (27.6\%) and 100\% specificity.

In patients with established $\mathrm{CD}$, the sensitivity and specificity of CE was found to be $77 \%$ to $100 \%$ and $53 \%$ to $100 \%$ in seven studies, respectively. ${ }^{14,17,19,22,25,31,33}$ The sensitivity and specificity of CTE were $76 \%$ to $82 \%$ and $85 \%$ to $89 \%$, respectively, in two studies. ${ }^{25,31}$ Moreover, the sensitivity and specificity of MRE were $77 \%$ to $81 \%$ and $80 \%$ to $90 \%$, respectively, in three studies. $^{14,31,33}$
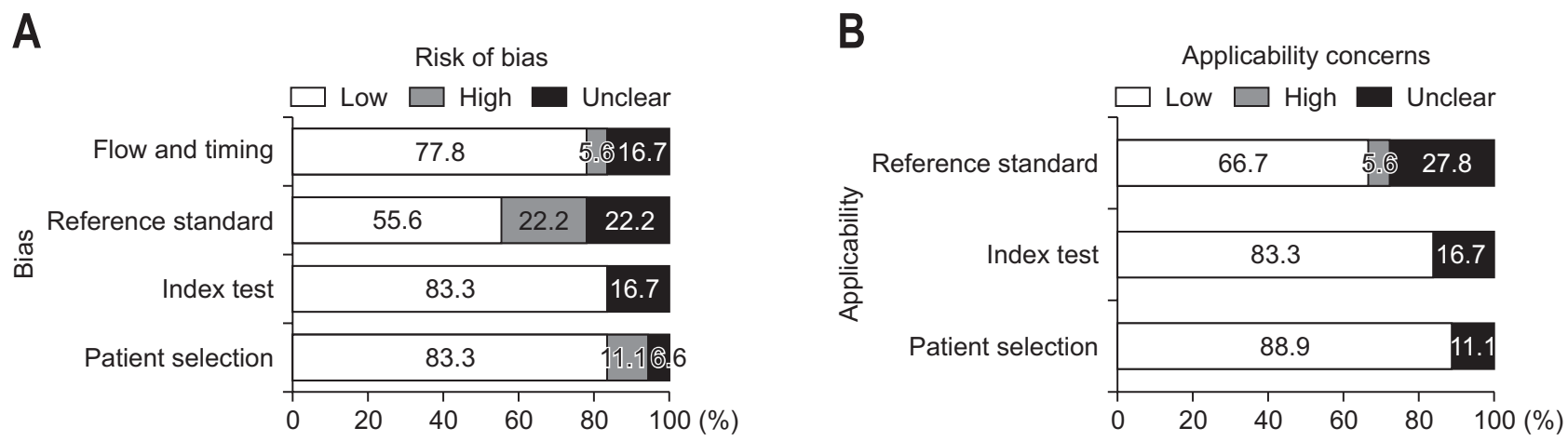

Fig. 2. Quality assessments of the included studies. (A) Risk of bias graph. (B) Applicability concerns graph. 
A CE vs SBFT

\begin{tabular}{|c|c|c|c|c|c|c|c|c|}
\hline \multirow[b]{2}{*}{ Study of subgroup } & \multicolumn{2}{|c|}{ CE } & \multicolumn{2}{|c|}{ SBFT } & \multirow[b]{2}{*}{ Weight } & \multirow{2}{*}{$\frac{\text { IYw }}{2}$} & \multirow{2}{*}{\multicolumn{2}{|c|}{$\begin{array}{c}\mathrm{IYw} \\
\mathrm{M}-\mathrm{H}, \text { random, } 95 \% \mathrm{Cl}\end{array}$}} \\
\hline & Events & Total & Events & Total & & & & \\
\hline Costamagna et al. (2002) & 9 & 20 & 4 & 20 & $22.9 \%$ & $0.25(-0.03,0.53)$ & & - \\
\hline Dubcenco et al. $(2005)^{16}$ & 26 & 39 & 8 & 39 & $38.8 \%$ & $0.46(0.27,0.66)$ & & - \\
\hline Eliakim et al. $(2004)^{13}$ & 27 & 35 & 8 & 35 & $38.3 \%$ & $0.54(0.35,0.74)$ & & \\
\hline $\begin{array}{l}\text { Total }(95 \% \mathrm{Cl}) \\
\text { Total events }\end{array}$ & 62 & 94 & 20 & 94 & $100.0 \%$ & $0.44(0.29,0.59)$ & & \\
\hline $\begin{array}{l}\text { Heterogeneity: } \operatorname{Tau}^{2}=0.01, \mathrm{C} \\
\text { Test for overall effect } Z=5.82\end{array}$ & $\begin{array}{l}C h i^{2}=2.8 \\
2(p<0.0\end{array}$ & $\begin{array}{l}\mathrm{df}=2 \\
001)\end{array}$ & $(p=0.24)$ & $=30 \%$ & & -1 & $\stackrel{-0.5}{\text { SBFT }}$ & $0 \quad C E^{0.5}$ \\
\hline
\end{tabular}

\section{B CE vs EC}

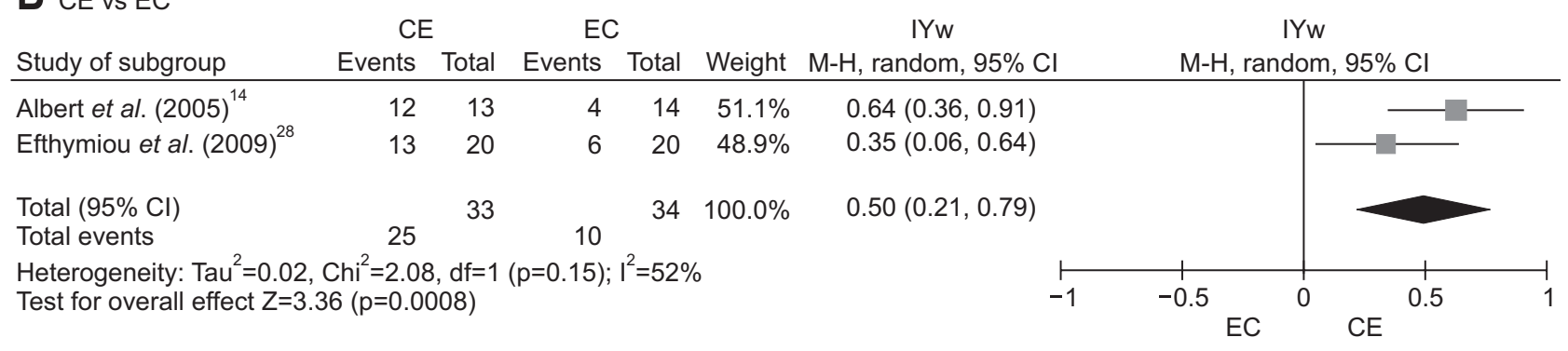

\section{CEvs CTE}

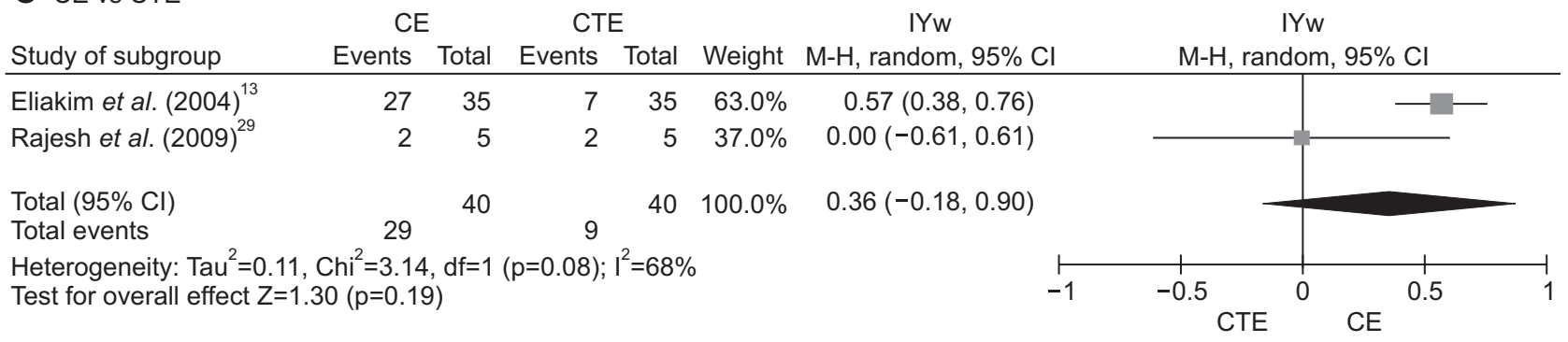

\section{CE vs MRE}

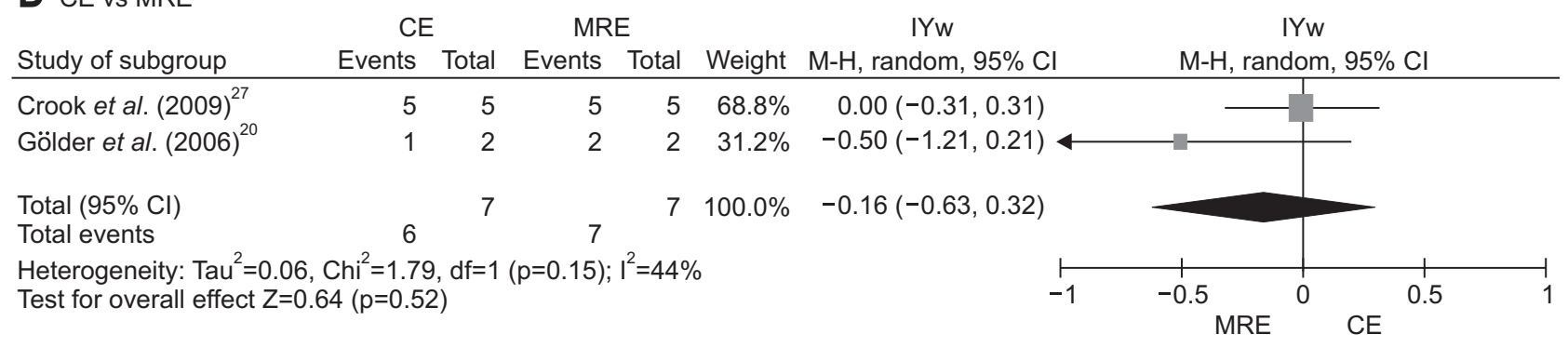

Fig. 3. Comparison of the diagnostic yield of different modalities for suspected Crohn's disease. (A) Comparison of the diagnostic yields of CE and SBFT. (B) Comparison of the diagnostic yields of CE and EC. (C) Comparison of the diagnostic yields of CE and CTE. (D) Comparison of the diagnostic yields of CE and MRE.

CE, capsule endoscopy; SBFT, small bowel follow-through; IYw, weighted incremental yield; CI, confidence interval; EC, enteroclysis; CTE, computed tomography enterography; MRE, magnetic resonance enterography.

\section{Detection of the terminal ileum lesion}

In the detection of lesions in the terminal ileum in cases of established $\mathrm{CD}$, the use of $\mathrm{CE}$ was compared to the use of ileocolonoscopy (IC) or CTE (Fig. 5) in five studies. ${ }^{18,19,22,24,31}$ The diagnostic yield of CE was statistically higher than that of IC (CE, 60\% vs IC, 48\%; IYw, 0.11; 95\% CI, 0.00 to 0.22 ; $\mathrm{I}^{2}$, 55\%). However, the diagnostic yield of $\mathrm{CE}$ was not superior to that of CTE (CE, 40\% vs CTE, 32\%; IYw, 0.08; 95\% CI, -0.02 to 0.19; I²,
$84 \%)$.

\section{Additional diagnostic gain}

A total four studies reported the additional lesions detected by CE. CE identified 40\% (12/30) more lesions as compared to SBFT and small intestine contrast ultrasonography. ${ }^{32}$ Moreover, CE identified a mucosal lesion in six patients who showed normal results on SBFT. ${ }^{12}$ Furthermore, CE showed additional lesions that were not detected on MRE $(9 / 52) .{ }^{26}$ With regard to the 
A CE vs SBFT

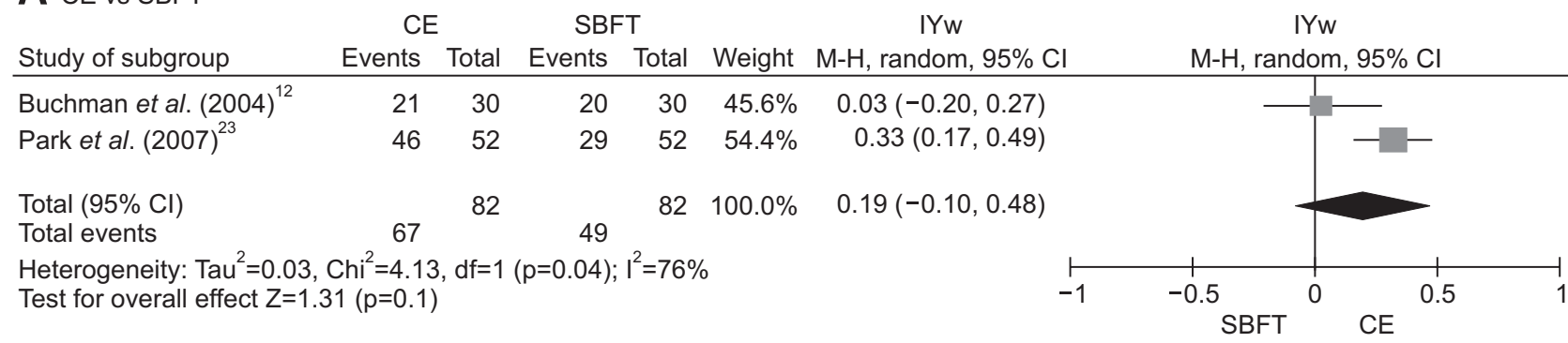

B CE vs EC

CE $\quad$ EC IYw

Study of subgroup Events Total Events Total Weight $\mathrm{M}-\mathrm{H}$, random, $95 \% \mathrm{Cl}$

IYw

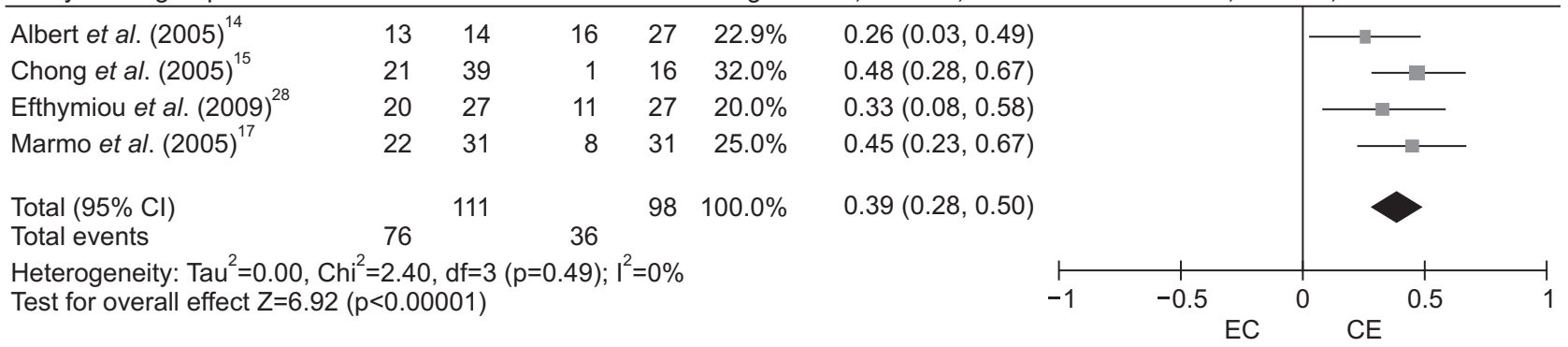

C CE vs CTE

Study of subgroup Events Total Events Total Weight $\mathrm{M}-\mathrm{H}$, random, $95 \% \mathrm{Cl}$

IYw IYw

\begin{tabular}{lrrrrrr}
\hline Jensen et al. $(2011)^{31}$ & 24 & 80 & 26 & 80 & $34.7 \%$ & $-0.03(-0.17,0.12)$ \\
Solem et al. $(2008)^{25}$ & 17 & 27 & 10 & 41 & $26.8 \%$ & $0.39(0.16,0.61)$ \\
Voderholzer et al. (2005) & 56 & 146 & 42 & 164 & $38.5 \%$ & $0.13(0.02,0.23)$ \\
& & & & & & \\
Total (95\% Cl) & 97 & 253 & & 285 & $100.0 \%$ & $0.14(-0.04,0.33)$ \\
Total events & & 78 & & &
\end{tabular}

Heterogeneity: $\operatorname{Tau}^{2}=0.02, \mathrm{Chi}^{2}=9.29, \mathrm{df}=2(\mathrm{p}=0.24) ; \mathrm{I}^{2}=78 \%$

Test for overall effect $Z=1.51(p=0.13)$

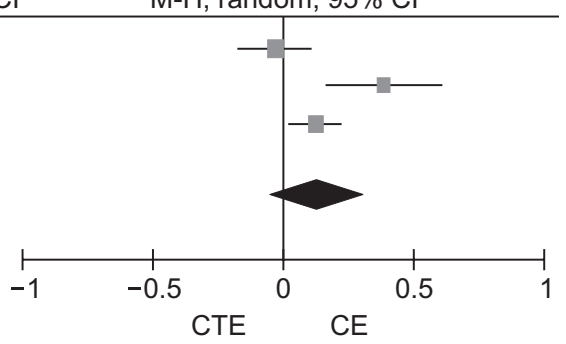

D CE vs MRE

Study of subgroup $\quad$ Events Total Events Total Weight $\mathrm{M}-\mathrm{H}$, random, $95 \% \mathrm{Cl}$

\begin{tabular}{|c|c|c|c|c|c|c|}
\hline Albert et al. (2005) & 13 & 14 & 22 & 25 & $32.8 \%$ & $0.05(-0.14,0.23)$ \\
\hline Gölder et al. $(2006)^{20}$ & 9 & 16 & 6 & 16 & $9.8 \%$ & $0.19(-0.15,0.53)$ \\
\hline Jensen et al. (2011) & 24 & 80 & 22 & 80 & $57.4 \%$ & $0.02(-0.12,0.17)$ \\
\hline $\begin{array}{l}\text { Total }(95 \% \mathrm{Cl}) \\
\text { Total events }\end{array}$ & 46 & 110 & 50 & 121 & $100.0 \%$ & $0.05(-0.06,0.15)$ \\
\hline
\end{tabular}

Heterogeneity: $\mathrm{Tau}^{2}=0.00, \mathrm{Chi}^{2}=0.75, \mathrm{df}=2(\mathrm{p}=0.69) ; \mathrm{I}^{2}=0 \%$

Test for overall effect $Z=0.90(p=0.37)$

E CE vs IC

Study of subgroup Events Total Events Total Weight $\mathrm{M}-\mathrm{H}$, random, $95 \% \mathrm{Cl}$

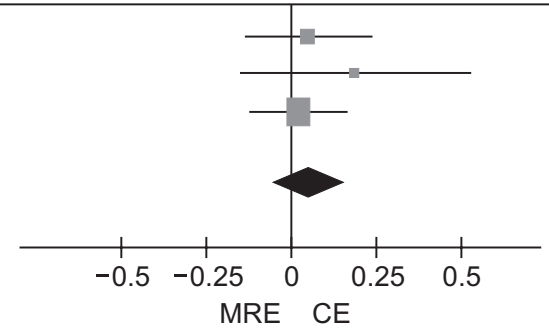

\begin{tabular}{lllllll}
\hline Biancone et al. $(2007)^{22}$ & 35 & 39 & 35 & 39 & $53.0 \%$ & $0.00(-0.13,0.13)$
\end{tabular}

$\begin{array}{lllllll}\text { Pons Beltrán et al. }(2007)^{24} & 15 & 22 & 6 & 24 & 47.0 \% & 0.43\end{array}$

Total $(95 \% \mathrm{Cl})$

61

$63100.0 \%$

$0.20(-0.25,0.66)$

Heterogeneity: $\operatorname{Tau}^{2}=0.10, \mathrm{Chi}^{2}=9.60, \mathrm{df}=1(\mathrm{p}=0.002) ; \mathrm{I}^{2}=90 \%$

Test for overall effect $Z=0.88(p=0.38)$

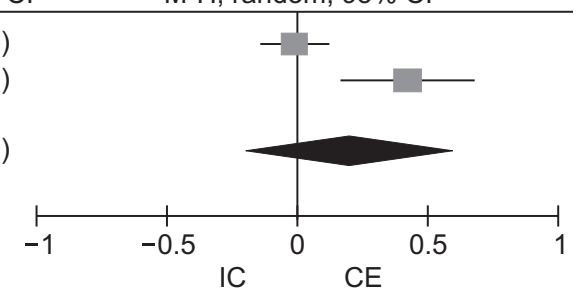

Fig. 4. Comparison of the diagnostic yield of different modalities for established Crohn's disease. (A) Comparison of the diagnostic yields of CE and SBFT. (B) Comparison of the diagnostic yields of CE and EC. (C) Comparison of the diagnostic yields of CE and CTE. (D) Comparison of the diagnostic yields of CE and MRE. (E) Comparison of the diagnostic yields of CE and IC.

CE, capsule endoscopy; SBFT, small bowel follow-through; IYw, weighted incremental yield; CI, confidence interval; EC, enteroclysis; CTE, computed tomography enterography; MRE, magnetic resonance enterography; IC, ileocolonoscopy. 
Table 2. Diagnostic Accuracy

\begin{tabular}{|c|c|c|c|c|c|c|}
\hline Author (year) & Reference standard (N) & Population & Subgroup & $\begin{array}{l}\text { Modalities } \\
(\mathrm{N})\end{array}$ & $\begin{array}{c}\text { Sensitivity, } \\
\% \%\end{array}$ & $\begin{array}{c}\text { Specificity, } \\
\%\end{array}$ \\
\hline \multicolumn{7}{|l|}{ Suspected CD } \\
\hline \multirow[t]{2}{*}{ Albert et al. (2005) ${ }^{14}$} & All clinical data including IC (52) & Suspected CD & - & $\mathrm{CE}(25)$ & 92.0 & 100.0 \\
\hline & & & & MRE (25) & 77.0 & 80.0 \\
\hline \multirow[t]{2}{*}{ Dubcenco et al. $(2005)^{16}$} & IC (39) & Suspected CD & - & CE (39) & 89.6 & 100.0 \\
\hline & & & & SBFT (39) & 27.6 & 100.0 \\
\hline \multicolumn{7}{|l|}{ Established CD } \\
\hline \multirow[t]{2}{*}{ Albert et al. (2005) ${ }^{14}$} & All data including IC (52) & Established CD & - & CE (27) & 92.0 & 100.0 \\
\hline & & & & MRE (27) & 77.0 & 80.0 \\
\hline \multirow[t]{2}{*}{ Marmo et al. (2005) ${ }^{17}$} & Comprehensive decision (31) & Established CD & Established terminal ileum & CE (16) & 87.0 & - \\
\hline & & & & EC (16) & 37.0 & - \\
\hline \multirow[t]{4}{*}{ Bourreille et al. (2006) ${ }^{19}$} & Ileoscopy (32) & Established CD & Lower & $\mathrm{CE}(31)$ & 62.0 & 90.0 \\
\hline & & & Upper & & 76.0 & 100.0 \\
\hline & & & Lower & IC (31) & 86.0 & 50.0 \\
\hline & & & Upper & & 86.0 & 79.0 \\
\hline \multirow[t]{2}{*}{ Biancone et al. $(2007)^{22}$} & IC (22) & Established CD & Recurrence & $\mathrm{CE}(22)$ & 100.0 & 100.0 \\
\hline & & & Terminal ileum recur & CE (17) & 93.0 & 67.0 \\
\hline \multirow[t]{2}{*}{ Solem et al. (2008) ${ }^{25}$} & Expert consensus (41) & Established CD & & $\mathrm{CE}(27)$ & 83.0 & 53.0 \\
\hline & & & & CTE (41) & 82.0 & 89.0 \\
\hline \multirow[t]{3}{*}{ Jensen et al. $(2011)^{31}$} & IC, IC+surgery, surgery (75) & Established CD & - & CE (87) & 100.0 & 91.0 \\
\hline & & & & MRE (89) & 81.0 & 86.0 \\
\hline & & & & CTE (90) & 76.0 & 85.0 \\
\hline \multirow[t]{2}{*}{ Wiarda et al. $(2012)^{33}$} & BAE+expert consensus (38) & Established CD & - & CE (38) & 57.1 & 88.9 \\
\hline & & & & MRE (38) & 76.7 & 89.5 \\
\hline
\end{tabular}

CD, Crohn's disease; IC, ileocolonoscopy; CE, capsule endoscopy; MRE, magnetic resonance enterography; SBFT, small bowel follow-through; EC, enteroclysis; CTE, computed tomography enterography; BAE, balloon-assisted enteroscopy.

detection of recurrent lesions in the terminal ileum, CE showed two more lesions as compared to IC. ${ }^{19}$

The satisfaction of patients with CE, as compared to other modalities, has been reported in two studies. Patients preferred CE to MRE or balloon-assisted enteroscopy (2.73 vs 1.43 and $1.85, \mathrm{p}<0.001$ ) due to the lower burden of the examination in terms of discomfort during insertion, pain, and difficulty in swallowing. ${ }^{34}$ Moreover, CE was preferred to IC. Patients experienced greater discomfort during examination preparation and daily activities with IC (80\%) than with CE (20\%). ${ }^{24}$

\section{Safety-related outcomes}

A total of eight studies reported adverse events related to CE (Table 3). ${ }^{12,18,21,23,25,26,32,33}$ The most common adverse event included capsule retention (5.5\%, 14 of 255 patients). Capsule malfunction was reported in one study (one of 28 patients), and abdominal pain was reported in one study. Incomplete examination results were reported in five studies (Table 4). ${ }^{14,15,17,21,28}$ However, incomplete examination results in CE were only noted in $7.5 \%$ patients (12 of 160 patients), as compared to those noted in other modalities (MRE, 12\%; IC, 24\%; and EC, 10.5\%).

\section{DISCUSSION}

In the present study, we provided updated information from published relevant systematic reviews, and focused on the additional diagnostic gain with the use of $\mathrm{CE}$ in the clinical field. Similar previous meta-analyses focused on a comparison of the diagnostic yield; however, these studies included data from abstracts that were excluded in the present study as they yield inconsistent result. ${ }^{7,835}$ For a more precise comparison of diagnostic yield, we only included published studies, and divided the patients into cases with suspected and established CD. Moreover, a subgroup analysis was performed to identify the effectiveness of the diagnosis of terminal ileum lesions. Furthermore, we attempted to identify the additional diagnostic information or benefits in $\mathrm{CD}$ patients, including patient preference or satisfaction as well as adverse events.

Previous studies assumed that there would be different benefits for each patient group, and they indicated different results based on each patient group. ${ }^{7,8,35}$ In the present study, the diagnostic yield of CE was found to be superior to that of other modalities in several subgroup comparisons, although not all the comparisons showed consistency in effectiveness. In cases of 
A CE vs IC

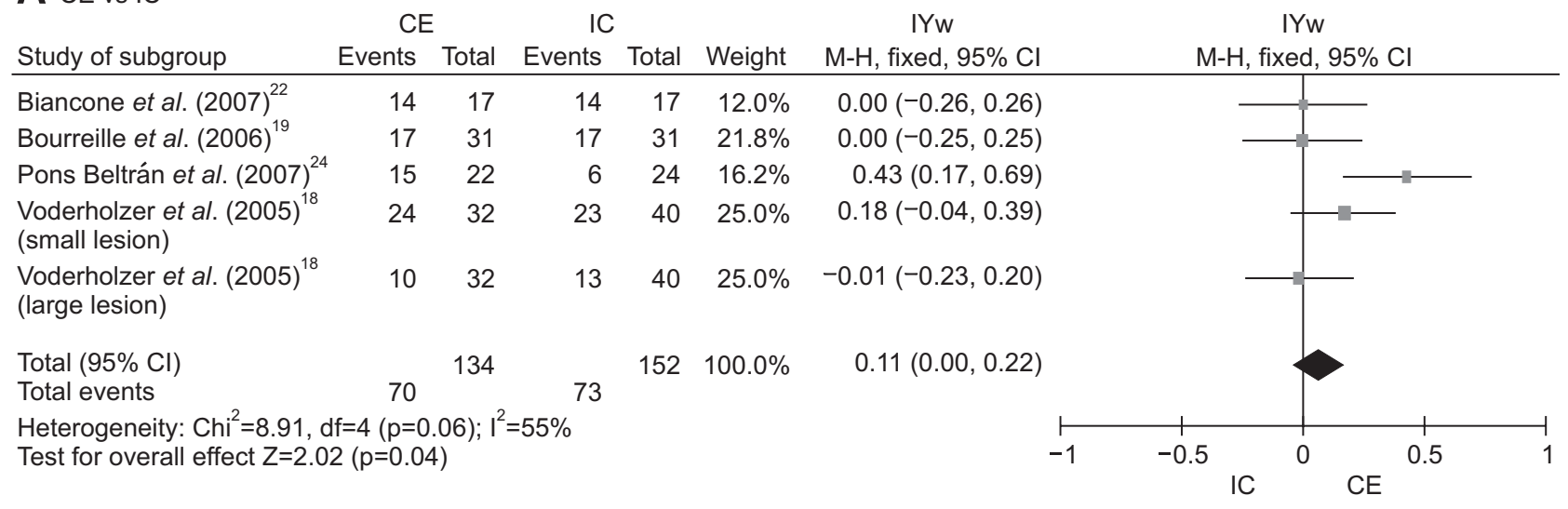

\section{B CE vs CTE}

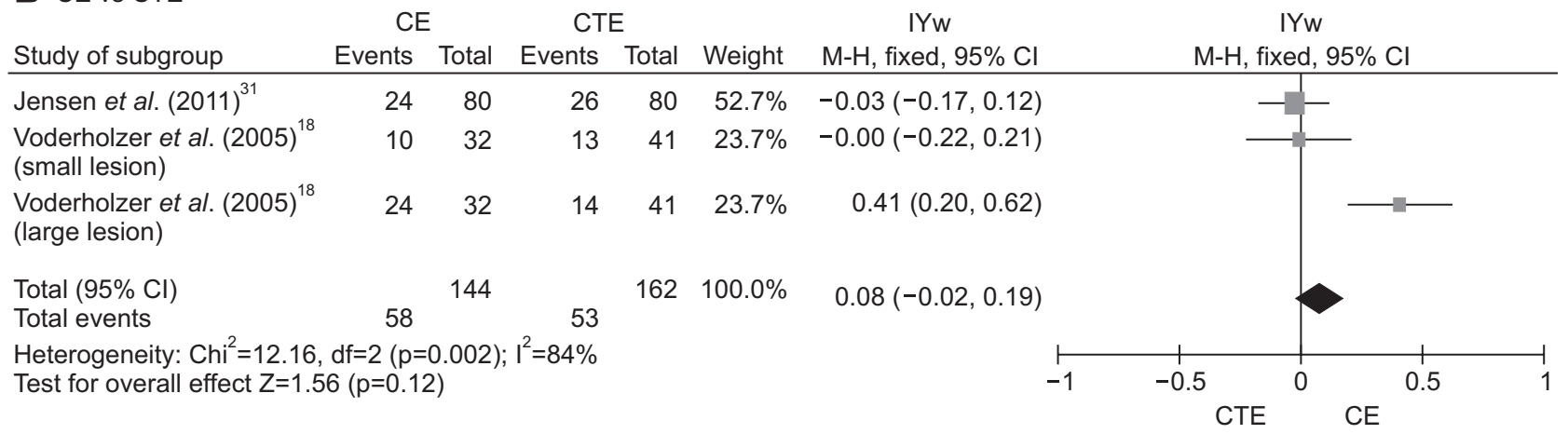

Fig. 5. Comparison of the diagnostic yield of different modalities for the detection of a terminal ileum lesion. (A) Comparison of the diagnostic yields of CE and IC. (B) Comparison of the diagnostic yields of CE and CTE.

CE, capsule endoscopy; IC, ileocolonoscopy; IYw, weighted incremental yield; CI, confidence interval; CTE, computed tomography enterography.

Table 3. Capsule-Related Adverse Events

\begin{tabular}{lccl}
\hline \multicolumn{1}{c}{ Author (year) } & Capsule retention, \% (n/N) & Capsule malfunction, \% (n/N) & \multicolumn{1}{c}{ Cause (n) } \\
\hline Buchman et al. $(2004)^{12}$ & $6.7(2 / 30)$ & - & Small bowel stenosis (2) \\
Voderholzer et al. (2005) $^{18}$ & $4.9(2 / 41)$ & - & Terminal ileum inflammation (1), jejunal stenosis (1) \\
Hara et al. (2006) & $5.9(1 / 17)$ & - & Small bowel stenosis (1) \\
Park et al. (2007) & $9.6(5 / 52)$ & - & Small bowel stenosis (5) \\
Solem et al. $(2008)^{25}$ & - & $3.6(1 / 28)$ & Technical failure (1) \\
Tillack et al. $(2008)^{26}$ & $5.3(1 / 19)$ & - & Site of stenosis \\
Petruzziello et al. $(2011)^{32}$ & $3.3(1 / 30)$ & - & Ulcerated stenosis (1) \\
Wiarda et al. $(2012)^{33}$ & $2.6(1 / 38)$ & - & Small bowel stenosis (1) \\
\hline
\end{tabular}

suspected CD, CE showed a higher diagnostic yield as compared to SBFT and EC. As no reference standard has been established, it is difficult to identify lesions in asymptomatic patients; however, an advantage of $\mathrm{CE}$ is that it enables the visualization of the entire small bowel, and hence, small bowel lesions can be easily and directly detected. ${ }^{36}$ Our results may reflect this phenomenon. In contrast, in cases of established CD, CE showed a higher diagnostic yield as compared to EC; this has been also observed in previous studies. ${ }^{7,8}$ A previous meta-analysis on CE indicated that it had a higher diagnostic yield as compared to
CTE in the cases with established disease and not in the cases with suspected disease. ${ }^{8}$ However, that study included abstracts and studies that were still in press. $\mathrm{CD}$ is frequently accompanied by extraluminal inflammation. In such cases, CTE and MRE may serve as more useful diagnostic modalities. ${ }^{37}$ Thus, our results reflect the strengths and limitations of CE.

In most patients with $\mathrm{CD}$, the lesions are located in the terminal ileum, which can be accessed by IC. ${ }^{36}$ Previous metaanalyses did not report any comparisons of modalities based on the lesions of this area; however, we performed such a compari- 
Table 4. Incomplete Examination Rate and Causes

\begin{tabular}{|c|c|c|c|c|c|c|}
\hline \multirow{2}{*}{ Author (year) } & \multicolumn{2}{|r|}{ Index test } & \multicolumn{4}{|c|}{ Comparators } \\
\hline & $\mathrm{CE}, \%(\mathrm{n} / \mathrm{N})$ & Cause, $\%$ (n) & MRE, \% (n/N) & $\mathrm{IC}, \%(\mathrm{n} / \mathrm{N})$ & $\mathrm{EC}, \mathrm{o}(\mathrm{n} / \mathrm{N})$ & Cause (n) \\
\hline Albert et al. (2005) ${ }^{14}$ & $7.1(1 / 14)$ & Retention (1) & $12.0(3 / 25)$ & - & $8.3(2 / 24)$ & - \\
\hline Chong et al. (2005) ${ }^{15}$ & $2.3(1 / 43)$ & Dysphagia (1) & - & - & $13.9(6 / 43)$ & $\begin{array}{l}\text { Tube insertion failure } \\
\text { and denial (6) }\end{array}$ \\
\hline Marmo et al. (2005) ${ }^{17}$ & $25.8(8 / 31)$ & $\begin{array}{l}\text { Cecum reach failure (2), } \\
\text { low quality of result (6) }\end{array}$ & - & - & $0(0 / 31)$ & - \\
\hline Hara et al. $(2006)^{21}$ & $11.7(2 / 17)$ & - & - & $23.5(4 / 17)$ & - & - \\
\hline Efthymiou et al. (2009) ${ }^{28}$ & $0(0 / 55)$ & - & - & - & $1.5(8 / 55)$ & Tube insertion failure (8) \\
\hline
\end{tabular}

CE, capsule endoscopy; MRE, magnetic resonance enterography; IC, ileocolonoscopy; EC, enteroclysis.

son in the subgroup analysis. With regard to the detection of the recurrence of terminal ileum lesions, CE has a more superior diagnostic yield than IC, but a comparable diagnostic yield with CTE. The small bowel beyond the duodenum and proximal to the terminal ileum is inaccessible in conventional endoscopy; ${ }^{36}$ therefore, CE would be a useful modality to examine terminal ileum lesions.

Although the included studies reported on the diagnostic accuracy, different reference standards have been used, as shown Table 1. SBFT and EC have been regarded as reference standard for radiographic assessment, but CTE and MRE are more accurate for the diagnosis of $\mathrm{CD} .{ }^{36}$ In the present study, we could not determine whether CE had a superior diagnostic performance as compared to MRE or CTE. CD can be accompanied by extraluminal inflammation, and MRE and CTE are relatively novel and enhanced radiographic diagnostic methods that are more accurate for diagnosis as compared to SBFT or EC in such cases. ${ }^{36}$ Moreover, MRE is particularly useful for detecting transmural inflammation, stenosis, and extraintestinal lesions including abscesses and fistula. ${ }^{26,37}$ However, diagnostic effectiveness should not be judged based on diagnostic performance alone. The characteristics of CD such as systemic inflammation as well as recurrence are difficult to detect. ${ }^{37} \mathrm{CE}$ shows the entire small bowel through the canal, and has a higher successful completion rate than other endoscopic modalities. One systematic review reported a pooled completion rate of CE of $84.4 \%$, wherein single-arm studies were included. ${ }^{38}$

Moreover, patient preference and additional diagnostic gain should be considered in the clinical decision. Patient satisfaction was higher in the CE group, in terms of comfort during the procedure, as compared to other diagnostic methods. The most frequent adverse event related to CE was capsule retention. In the present study, the capsule retention rate was 5.4\%. One systematic review reported a retention rate of $2.6 \%$, although this review included single-arm studies, and hence included a large number of studies. ${ }^{38}$ A previous study of a large cohort reported a retention rate of $8.3 \%$ in $\mathrm{CD} .^{39}$ Capsule retention primarily occurs in cases of luminal stricture and stenosis. ${ }^{26}$ Therefore, in cases without stricture or stenosis of the bowel lumen, the use of $\mathrm{CE}$ is appropriate, as the retention rate would be acceptable.

This study has certain limitations. As the heterogeneity of the data was high, we performed subgroup analysis according to the patients and modalities. Therefore, the number of studies included in each subgroup analysis was too small to determine whether the effectiveness was significant. Moreover, there were differences in the reference standards and procedure settings, such as the interval of test timing and patient severity; this may also affect heterogeneity. In those studies used in this metaanalysis, as the patients of $\mathrm{CD}$ with known strictures which can be present in up to $25 \%$ of $\mathrm{CD}$ were excluded, the results have shown the yield of CE in a subgroup of patients with nonstricturing $\mathrm{CD}$. If this population was included in the meta-analysis, the diagnostic yield of CTE and MRE would be higher. Other than that, the lack of a reference and/or gold standard may results in a confirmation bias, which may favor CE. CE found small bowel abnormality in about $20 \%$ of asymptomatic control patients, ${ }^{40}$ suggesting that many findings on CE maybe nonspecific and unrelated to the $\mathrm{CD}$.

Our meta-analysis demonstrates that CE is superior to SBFT and EC in the evaluation of suspected CD. CE is also a more effective diagnostic modality in patients with established CD, as compared to EC. Moreover, other modalities such as CTE or MRE showed a similar diagnostic performance compared to CE. However, CE may be an effective diagnostic method to diagnose patients who do not show any abnormality in radiographic screening without the risk of stricture or stenosis. Moreover, CE can be more helpful in identifying terminal ileum lesions as compared to IC. In addition, patients appear to prefer CE over other modalities.

Larger prospective studies are needed to establish the role of CE for diagnosing suspected small bowel CD and evaluating established CD. As it is unknown whether these results will translate into improved patient outcomes or decrease health care expenditures with CE versus other modalities, randomized controlled trials will be necessary to answer these questions. 


\section{CONFLICTS OF INTEREST}

No potential conflict of interest relevant to this article was reported.

\section{ACKNOWLEDGEMENTS}

This study was funded by the National Evidence-based Healthcare Collaborating Agency (NECA), project number: NECA-C-14-008.

\section{REFERENCES}

1. Baumgart DC, Sandborn WJ. Crohn's disease. Lancet 2012;380: 1590-1605.

2. Gower-Rousseau C, Vasseur F, Fumery M, et al. Epidemiology of inflammatory bowel diseases: new insights from a French population-based registry (EPIMAD). Dig Liver Dis 2013;45:89-94.

3. Nuij VJ, Zelinkova Z, Rijk MC, et al. Phenotype of inflammatory bowel disease at diagnosis in the Netherlands: a population-based inception cohort study (the Delta Cohort). Inflamm Bowel Dis 2013;19:2215-2222.

4. Sjöberg D, Holmström T, Larsson M, et al. Incidence and clinical course of Crohn's disease during the first year-results from the IBD Cohort of the Uppsala Region (ICURE) of Sweden 2005-2009. J Crohns Colitis 2014;8:215-222.

5. Yang SK, Yun S, Kim JH, et al. Epidemiology of inflammatory bowel disease in the Songpa-Kangdong district, Seoul, Korea, 1986-2005: a KASID study. Inflamm Bowel Dis 2008;14:542-549.

6. Abdul-Baki H, ElHajj I, El-Zahabi LM, et al. Clinical epidemiology of inflammatory bowel disease in Lebanon. Inflamm Bowel Dis 2007;13:475-480.

7. Triester SL, Leighton JA, Leontiadis GI, et al. A meta-analysis of the yield of capsule endoscopy compared to other diagnostic modalities in patients with non-stricturing small bowel Crohn's disease. Am J Gastroenterol 2006;101:954-964.

8. Dionisio PM, Gurudu SR, Leighton JA, et al. Capsule endoscopy has a significantly higher diagnostic yield in patients with suspected and established small-bowel Crohn's disease: a metaanalysis. Am J Gastroenterol 2010;105:1240-1248.

9. Whiting PF, Rutjes AW, Westwood ME, et al. QUADAS-2: a revised tool for the quality assessment of diagnostic accuracy studies. Ann Intern Med 2011;155:529-536.

10. Higgins JP, Green S. Cochrane handbook for systematic reviews of interventions. Chichester: Wiley-Blackwell, 2008.

11. Costamagna G, Shah SK, Riccioni ME, et al. A prospective trial comparing small bowel radiographs and video capsule endoscopy for suspected small bowel disease. Gastroenterology 2002;123:999-1005.

12. Buchman AL, Miller FH, Wallin A, Chowdhry AA, Ahn C. Videocapsule endoscopy versus barium contrast studies for the diagnosis of Crohn's disease recurrence involving the small intestine. Am
J Gastroenterol 2004;99:2171-2177.

13. Eliakim R, Suissa A, Yassin K, Katz D, Fischer D. Wireless capsule video endoscopy compared to barium follow-through and computerised tomography in patients with suspected Crohn's disease: final report. Dig Liver Dis 2004;36:519-522.

14. Albert JG, Martiny F, Krummenerl A, et al. Diagnosis of small bowel Crohn's disease: a prospective comparison of capsule endoscopy with magnetic resonance imaging and fluoroscopic enteroclysis. Gut 2005;54:1721-1727.

15. Chong AK, Taylor A, Miller A, Hennessy O, Connell W, Desmond P. Capsule endoscopy vs. push enteroscopy and enteroclysis in suspected small-bowel Crohn's disease. Gastrointest Endosc 2005;61:255-261.

16. Dubcenco E, Jeejeebhoy KN, Petroniene R, et al. Capsule endoscopy findings in patients with established and suspected smallbowel Crohn's disease: correlation with radiologic, endoscopic, and histologic findings. Gastrointest Endosc 2005;62:538-544.

17. Marmo R, Rotondano G, Piscopo R, et al. Capsule endoscopy versus enteroclysis in the detection of small-bowel involvement in Crohn's disease: a prospective trial. Clin Gastroenterol Hepatol 2005;3:772-776.

18. Voderholzer WA, Beinhoelzl J, Rogalla P, et al. Small bowel involvement in Crohn's disease: a prospective comparison of wireless capsule endoscopy and computed tomography enteroclysis. Gut 2005;54:369-373.

19. Bourreille A, Jarry M, D’Halluin PN, et al. Wireless capsule endoscopy versus ileocolonoscopy for the diagnosis of postoperative recurrence of Crohn’s disease: a prospective study. Gut 2006;55:978983.

20. Gölder SK, Schreyer AG, Endlicher E, et al. Comparison of capsule endoscopy and magnetic resonance (MR) enteroclysis in suspected small bowel disease. Int J Colorectal Dis 2006;21:97-104.

21. Hara AK, Leighton JA, Heigh RI, et al. Crohn disease of the small bowel: preliminary comparison among CT enterography, capsule endoscopy, small-bowel follow-through, and ileoscopy. Radiology 2006;238:128-134.

22. Biancone L, Calabrese E, Petruzziello C, et al. Wireless capsule endoscopy and small intestine contrast ultrasonography in recurrence of Crohn's disease. Inflamm Bowel Dis 2007;13:1256-1265.

23. Park CH, Kim JO, Choi MG, et al. Utility of capsule endoscopy for the classification of Crohn's disease: a multicenter study in Korea. Dig Dis Sci 2007;52:1405-1409.

24. Pons Beltrán V, Nos P, Bastida G, et al. Evaluation of postsurgical recurrence in Crohn's disease: a new indication for capsule endoscopy? Gastrointest Endosc 2007;66:533-540.

25. Solem CA, Loftus EV Jr, Fletcher JG, et al. Small-bowel imaging in Crohn's disease: a prospective, blinded, 4-way comparison trial. Gastrointest Endosc 2008;68:255-266.

26. Tillack C, Seiderer J, Brand S, et al. Correlation of magnetic resonance enteroclysis (MRE) and wireless capsule endoscopy (CE) in the diagnosis of small bowel lesions in Crohn's disease. Inflamm Bowel Dis 2008;14:1219-1228. 
27. Crook DW, Knuesel PR, Froehlich JM, et al. Comparison of magnetic resonance enterography and video capsule endoscopy in evaluating small bowel disease. Eur J Gastroenterol Hepatol 2009;21:54-65.

28. Efthymiou A, Viazis N, Vlachogiannakos J, et al. Wireless capsule endoscopy versus enteroclysis in the diagnosis of small-bowel Crohn's disease. Eur J Gastroenterol Hepatol 2009;21:866-871.

29. Rajesh A, Sandrasegaran K, Jennings SG, et al. Comparison of capsule endoscopy with enteroclysis in the investigation of small bowel disease. Abdom Imaging 2009;34:459-466.

30. Böcker U, Dinter D, Litterer C, et al. Comparison of magnetic resonance imaging and video capsule enteroscopy in diagnosing small-bowel pathology: localization-dependent diagnostic yield. Scand J Gastroenterol 2010;45:490-500.

31. Jensen MD, Nathan T, Rafaelsen SR, Kjeldsen J. Diagnostic accuracy of capsule endoscopy for small bowel Crohn's disease is superior to that of MR enterography or CT enterography. Clin Gastroenterol Hepatol 2011;9:124-129.

32. Petruzziello C, Calabrese E, Onali S, et al. Small bowel capsule endoscopy vs conventional techniques in patients with symptoms highly compatible with Crohn's disease. J Crohns Colitis 2011;5:139-147.

33. Wiarda BM, Mensink PB, Heine DG, et al. Small bowel Crohn's disease: MR enteroclysis and capsule endoscopy compared to balloon-assisted enteroscopy. Abdom Imaging 2012;37:397-403.
34. Wiarda BM, Stolk M, Heine DG, et al. Patient burden and patient preference: comparing magnetic resonance enteroclysis, capsule endoscopy and balloon-assisted enteroscopy. J Gastroenterol Hepatol 2013;28:464-471.

35. Park SK, Ye BD, Kim KO, et al. Guidelines for video capsule endoscopy: emphasis on Crohn's disease. Clin Endosc 2015;48:128135

36. Bourreille A, Ignjatovic A, Aabakken L, et al. Role of small-bowel endoscopy in the management of patients with inflammatory bowel disease: an international OMED-ECCO consensus. Endoscopy 2009;41:618-637.

37. Naganuma M, Hosoe N, Kanai T, Ogata H. Recent trends in diagnostic techniques for inflammatory bowel disease. Korean J Intern Med 2015;30:271-278.

38. Liao Z, Gao R, Xu C, Li ZS. Indications and detection, completion, and retention rates of small-bowel capsule endoscopy: a systematic review. Gastrointest Endosc 2010;71:280-286.

39. Cheon JH, Kim YS, Lee IS, et al. Can we predict spontaneous capsule passage after retention? A nationwide study to evaluate the incidence and clinical outcomes of capsule retention. Endoscopy 2007;39:1046-1052.

40. Goldstein JL, Eisen GM, Lewis B, et al. Video capsule endoscopy to prospectively assess small bowel injury with celecoxib, naproxen plus omeprazole, and placebo. Clin Gastroenterol Hepatol 2005;3:133-141. 